\title{
Analytical study on inherent properties of a unidirectional vibrating steel strip partially immersed in fluid
}

\author{
J. Li*, X.H. Guo, J. Luo, H.Y. Li and Y.Q. Wang \\ Institute of Applied Mechanics, College of Science, Northeastern University, Shenyang, Liaoning, China
}

Received 21 July 2012

Revised 1 November 2012

Accepted 22 January 2013

\begin{abstract}
The theory of singuarity functions is introduced to present an analytical approach for the natural properties of a unidirectional vibrating steel strip with two opposite edges simply supported and other two free, partially submerged in fluid and under tension. The velocity potential and Bernoulli's equation are used to describe the fluid pressure acting on the steel strip. The effect of fluid on vibrations of the strip may be equivalent to added mass of the strip. The math formula of added mass can be obtained from kinematic boundary conditions of the strip-fluid interfaces. Singularity functions are adopted to solve problems of the strip with discontinuous characteristics. By applying Laplace transforms, analytical solutions for inherent properties of the vibrating steel strip in contact with fluid are finally acquired. An example is given to illustrate that the proposed method matches the numerical solution using the finite element method (FEM) very closely. The results show that fluid has strong effect on natural frequencies and mode shapes of vibrating steel strips partially dipped into a liquid. The influences such as tension, the submergence depth, the position of strip in the container and the dimension of the container on the dynamic behavior of the strip are also investigated. Moreover, the presented method can also be used to study vertical or angled plates with discontinuous characteristics as well as different types of pressure fields around.
\end{abstract}

Keywords: Singularity functions, velocity potential, added mass, Laplace transform, discontinuous characteristics

\section{Introduction}

Problems of interaction between thin plates and fluid have received extensive attention in recent decades. Many engineering applications have related interest, such as shipping and marine engineering, aerospace and aeronautical industries, noise control and vibration isolation. The objective of this article is to provide a new analytical method to investigate flexural vibration of a rectangular plate partially immersed in fluid. The plate is simply supported on two opposite edges and free on the other two edges, partially immersed within a tank containing fluid and under tension. The motivation of this work is to find an analytical approach for real time computation of a vibrating steel strip partially immersed in liquid zinc during the continuous hot-dip galvanizing process (Fig. 1). Vibrations of the steel strip need to be studied for vibration suppression of the steel strip near the zinc pot. Wind loads of air knife acting on the steel strip vertically are distributed uniformly across the width of the strip. The field test results in a continuous hot-dip galvanizing line had revealed that the wind load induce flexural vibrations in the axial direction of the strip. So the vibrations of the steel strip can be modeled by vibrations of unidirectional thin plate. In comparison with

*Corresponding author: J. Li, Institute of Applied Mechanics, College of Science, Northeastern University, Shenyang 110819, Liaoning, China. Tel.: +860248368 1645; E-mail: jianli@mail.neu.edu.cn. 


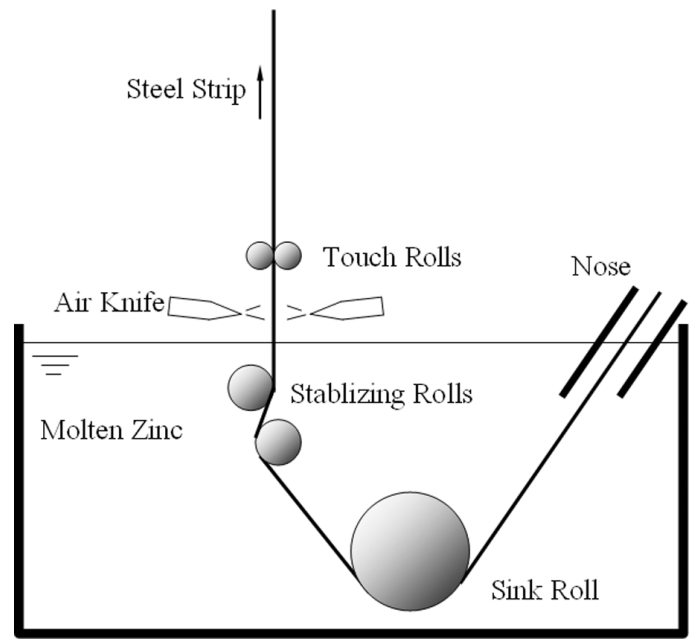

Fig. 1. Schematic diagram of a continuous hot-dip galvanizing line.

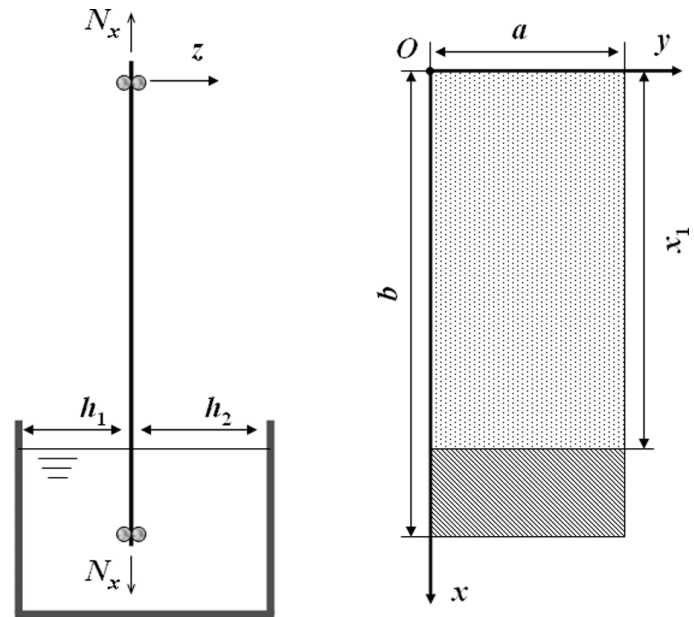

Fig. 2. The tensioned rectangular plate partially immersed in fluid with two simple supports.

cantilever plate, analytical solutions and experiments for vibration of the tensioned, partially submerged plate with simply supported on two opposite edges and free on the other two edges are seldom reported in open literatures. The presented method can easily be extended to further study on vibrations of a partially immersed plate with different types of pressure fields around.

A lot of research on problems involving dynamic interaction between an elastic structure and a surrounding fluid medium has been carried out. The original classic analysis of the problem by Lamb [1] was simple but elegant. He calculated the change in natural frequency of a thin circular plate fixed at its circumference, in contact with water. The natural frequency was determined using Rayleigh's method and based on a calculation of the kinetic energy of the liquid. Powell and Roberts [2] verified the theoretical results of Lamb's work by conducting experiments. In the following years, the classic model presented by Lamb [1] had been developed rapidly [3].

Considerable effort had been made in the study of a vibrational plate in contact with fluid. The most common objects were focused on cantilever plates [4-10]. The resonance frequencies of cantilever plates in air or partially immersed in water were investigated experimentally [4], and prediction of natural frequencies as well as modal patterns of plates in air and under water was considered. The experimental data showed good agreement with the results of an analytical approach based on the boundary-integral equation method and the method of images [9], but the research did not try to predict frequency response amplitudes.

Other geometries and boundary conditions for the plate also interested researchers continuously. Vibrations of the bottom in an arbitrarily shaped cylindrical container filled with fluid were studied [11,12]. The exact solution of the equations of motion was employed and the Fourier expansion collocation method was adopted to satisfy the boundary conditions. Investigations in the effect of the boundary conditions and the depth of submergence on the dynamic responses of rectangular plates immerged in fluid were also conducted [13,14]. The vibration analysis of a plate partially or totally immersed in liquid $[5,6,9]$ or a floating plate in contact with the free surface of fluid [15, 16] was implemented to study the interaction between the plate and fluid. Hankel transform was used to solve the mixed boundary problem for clamped, simply supported and free plates [16].

Added or virtual mass was usually employed to characterize the interaction of a plate with a fluid flowing around or over it $[3,7,8,12-14,16]$. Friedrich Bessel proposed the concept of added mass in 1828 to describe the motion of a pendulum in a fluid. Based on Rayleigh-Ritz method [7] or the assumption of a fundamental mode [8], researchers derived formulation for the evaluation of the modal added masses. They indicated that natural frequencies for any arbitrary shapes of plate with general boundary conditions can be determined by calculating the added virtual mass incremental factor provided that the natural frequencies of the fundamental mode had been acquired [14]. These results were then compared with other literatures and verified the theory experimentally [7,13,16].

The finite element method (FEM) was also introduced to solve the fluid-structure interaction problems for submerged plates $[17,18]$. The classical Naghdi equations and its approximation using the mixed interpolation of ten- 
sorial component 4 finite element method were considered for the plate or shell and Raviart-Thomas elements were employed to discretize equations of the fluid [18]. Recently, the effort attempted to solve a more complex situation such as a viscous [3,10], compressible [18] fluid and flutter. The Lamb's model [1] was extended and a Newtonian viscous fluid in contact with a vibrating plate aiming at evaluating the effect of viscosity on the added virtual mass was considered [3]. A linear form of the nonlinear Navier-Stokes equations was adopted to implement viscosity coupling the plate vibration to the tangential velocity of the fluid. An analytical stability analysis on the flutter of a rectangular cantilevered plate in an axial uniform flow was also carried out [19]. The Galerkin method and Fourier transforms were used to predict the flutter modes, their frequencies and growth rates.

In this paper, the analysis is based on the assumption that the fluid is inviscid and incompressible, and its motion is irrotational. The velocity potential and Bernoulli's equation are employed to express the fluid pressure acting on the structure. Singular function theory is introduced to obtain natural frequencies and mode shapes of vibrating plates with discontinuous characteristics. In the absence of available experiments in the open literature, a comparison between analytical solutions and results from the finite element method is given to demonstrate its validity.

\section{Theoretical analysis}

\subsection{Equations of motion for a unidirectional thin plate}

Consider the physical model of a rectangular plate partially immersed in fluid stated as in Fig. 2, where $a$ and $b$ represent the width and length of the rectangular plate, and $h$ is the thickness respectively. $x_{1}$ denotes the length of the plate out of the liquid. Axial tension $N_{x}$ is applied to the plate with two simply supports along loaded sides.

The plate is assumed to be made of linear elastic, homogeneous and isotropic material. Its material properties are mass density $\rho_{p}$, the Poisson ratio $\nu$, Young's modulus $E$ and the damping coefficient $c$. A Cartesian coordinate system $(x, y, z)$ is chosen, where $x$ is the axial and $z$ is the normal coordinate. The displacements of points of the middle surface of the plate are denoted by $w(x, y, t)$ in the normal direction. The effects of shear deformation and rotary inertia are neglected. The analysis is based on the standard theory of thin plates and only considers the case of flexural vibration of the plate in the $\mathrm{x}$ axis direction. So vibration of the plate partially immersed in liquid is governed by the following differential equation

$$
D \frac{\partial^{4} w}{\partial x^{4}}+c \frac{\partial w}{\partial t}+\rho_{p} h \frac{\partial^{2} w}{\partial t^{2}}-N_{x} \frac{\partial^{2} w}{\partial x^{2}}=\Delta p
$$

where $D=E h^{3} /\left[12\left(1-\nu^{2}\right)\right]$ is the flexural rigidity of a plate and $\Delta p$ is the pressure load of the surrounding liquid on the plate.

\subsection{Fluid action on plates}

It is well known that the presence of the fluid modifies the natural frequencies and mode shapes of the structure from those calculated in air. In general, the inherent properties of the plate in contact with the fluid can be determined by calculating the added virtual mass which represents the kinetic energy due to the fluid. The fluid force is superimposed upon the structure to form the dynamic equations of a coupled fluid-structure system. The rectangular plate is in partial contact with liquid on both sides. So in Eq. (1), $\Delta p$ is equal to the pressure difference between left and right surfaces of the plate and can be expressed as

$$
\Delta p=p_{\text {left }}-p_{\text {right }}
$$

where $p_{\text {left }}$ and $p_{\text {right }}$ denote the fluid pressure acting normal to left and right surfaces of the plate respectively. Here in the theoretical analysis, the fluid is assumed to be incompressible, irrotational and inviscid under plate vibration. The liquid behavior is considered to follow the potential flow theory. The velocity potential of the liquid is designated 
by $\phi(x, y, z, t)$ at spatial co-ordinate $x, y, z$ and time $t$. Then, Laplace's equation (the continuity equation) is given in the Cartesian coordinate system by

$$
\nabla^{2} \phi=\frac{\partial^{2} \phi}{\partial x^{2}}+\frac{\partial^{2} \phi}{\partial y^{2}}+\frac{\partial^{2} \phi}{\partial z^{2}}=0
$$

Using Bernoulli's equation the fluid pressure is determined by

$$
p=-\rho_{f} \frac{\partial \phi}{\partial t}
$$

where $\rho_{f}$ is mass density of fluid. Considering Eq. (4), Eq. (2) becomes

$$
\Delta p=-\rho_{f}\left(\left.\frac{\partial \phi}{\partial t}\right|_{z=0}-\left.\frac{\partial \phi}{\partial t}\right|_{z=h}\right)
$$

Substituting Eq. (5) into Eq. (1), the equation of motion for the partially submerged plate can the rewritten as

$$
D \frac{\partial^{4} w}{\partial x^{4}}+c \frac{\partial w}{\partial t}+\rho_{p} h \frac{\partial^{2} w}{\partial t^{2}}-N_{x} \frac{\partial^{2} w}{\partial x^{2}}=-\rho_{f}\left(\left.\frac{\partial \phi}{\partial t}\right|_{z=0}-\left.\frac{\partial \phi}{\partial t}\right|_{z=h}\right)
$$

The Laplace Eq. (3) is a linear homogeneous equation and boundaries described in Fig. 2 are simple geometric shapes which can be expressed in the form of separated variables. So the following separate variable relation is assumed for the potential velocity function $\phi$ which satisfies Eq. (3) [20]

$$
\phi(x, y, z, t)=F(z) S(x, y, t)
$$

where $F(z)$ and $S(x, y, t)$ are two separate functions to be determined.

At the plate-fluid interfaces, kinematic boundary conditions are established under the assumption of a permanent contact between the plate surface and the peripheral fluid layer. The conditions are described as the agreement between the out-of-plane velocity component of the fluid on the plate surface and the instantaneous rate of change of the plate displacement in the transversal direction and can be written as

$$
\left.\frac{\partial \phi}{\partial z}\right|_{z=h}=\frac{\partial w}{\partial t}
$$

The substitution of Eq. (7) into Eq. (8) yields

$$
S(x, y, t)=\frac{1}{\mathrm{~d} F(h) / \mathrm{d} z} \frac{\partial w}{\partial t}
$$

Using Eq. (7), Eq. (9) can be expressed as

$$
\phi(x, y, z, t)=\frac{F(z)}{\mathrm{d} F(h) / \mathrm{d} z} \frac{\partial w}{\partial t}
$$

The following differential equation of second order may be obtained by introducing Eq. (10) into Eq. (3)

$$
\frac{\mathrm{d}^{2} F(z)}{\mathrm{d} z^{2}}-\mu^{2} F(z)=0
$$

where $\mu=\pi \sqrt{(1 / a)^{2}+\left[1 /\left(b-x_{1}\right)\right]^{2}}$ [20]. The general solution of Eq. (11) can be defined as

$$
F(z)=A_{1} e^{\mu z}+A_{2} e^{-\mu z}
$$


where $A_{1}$ and $A_{2}$ are two unknown constants. The potential function $\phi$ must be verified for given boundary conditions at the fluid-structure interface. An alternative boundary condition should be satisfied as follows

$$
\left.\frac{\partial \phi}{\partial z}\right|_{z=h+h_{2}}=0
$$

Placing Eqs (10) and (12) into relation Eq. (13) results in the following expression concerning $\phi$ as

$$
\phi=\frac{e^{\mu z}+e^{2 \mu\left(h+h_{2}\right)} e^{-\mu z}}{\mu\left(e^{\mu h}-e^{2 \mu\left(h+h_{2}\right)} e^{-\mu h}\right)} \frac{\partial w}{\partial t}
$$

Applying Eq. (4), the fluid pressure acting on the right surface of the plate represented in Fig. 2 is determined as

$$
p_{\text {right }}=-\left.\rho_{f} \frac{\partial \phi}{\partial t}\right|_{z=h}
$$

The substitution of Eq. (14) into Eq. (15) produces

$$
p_{\text {right }}=-\rho_{f} \frac{e^{\mu h}+e^{\mu h+2 \mu h_{2}}}{\mu\left(e^{\mu h}-e^{\mu h+2 \mu h_{2}}\right)} \frac{\partial^{2} w}{\partial t^{2}}
$$

Similarly, the other boundary condition at the liquid-tank interface can be expressed as

$$
\left.\frac{\partial \phi}{\partial z}\right|_{z=-h_{1}}=0
$$

According to the same way as mentioned above, we can deduce equations as follows

$$
\phi=\frac{e^{\mu z+2 \mu h_{1}}+e^{-\mu z}}{\mu\left(e^{2 \mu h_{1}}-1\right)} \frac{\partial w}{\partial t}
$$

and

$$
p_{\text {left }}=-\left.\rho_{f} \frac{\partial \phi}{\partial t}\right|_{z=0}=-\rho_{f} \frac{e^{2 \mu h_{1}}+1}{\mu\left(e^{2 \mu h_{1}}-1\right)} \frac{\partial^{2} w}{\partial t^{2}}
$$

The introduction of Eq. (16) as well as Eq. (18) into relation Eq. (2), results in the following expression for the pressure difference between left and right surfaces of the plate

$$
\Delta p=-\frac{\rho_{f}}{\mu}\left[\frac{e^{2 \mu h_{1}}+1}{\left(e^{2 \mu h_{1}}-1\right)}+\frac{e^{2 \mu h_{2}}+1}{\left(e^{2 \mu h_{2}}-1\right)}\right] \frac{\partial^{2} w}{\partial t^{2}}
$$

Another way to describe expression Eq. (19) is written as

$$
\Delta p=-m_{\text {add }} \frac{\partial^{2} w}{\partial t^{2}}
$$

where $m_{\text {add }}$ is called area density of added mass. Its expression is

$$
m_{\mathrm{add}}=\frac{\rho_{f}}{\mu}\left[\frac{e^{2 \mu h_{1}}+1}{\left(e^{2 \mu h_{1}}-1\right)}+\frac{e^{2 \mu h_{2}}+1}{\left(e^{2 \mu h_{2}}-1\right)}\right]
$$

Intuitively, the plate vibrates as if its mass is increased by the mass of the virtual layer of vibrating fluid. This phenomenon is termed the added virtual mass effect. 


\subsection{Introduction of singularity functions}

Based on the analysis above, effect of fluid on the dynamic characteristic of the plate may be regarded as an excess introduction of added mass. So the thin plate can be divided into two parts: immersed and non-immersed. These two parts have the same rigidity but a different mass surface density. In this way, the partially submerged plate may be treated as a non-immersed plate with discontinuous characteristics. Singularity functions are used to investigate inherent properties of this plate.

Singularity functions are good tools to solve the problem on discontinuous characteristics. They are generally considered a family of functions as follows [21]

$$
f(x)=\left\langle x-x_{i}\right\rangle^{n}
$$

with

$$
\left\{\begin{array}{l}
n \geqslant 0, \quad\left\langle x-x_{i}\right\rangle^{n}= \begin{cases}\left(x-x_{i}\right)^{n}, & x \geqslant x_{i} \\
0, & x<x_{i}\end{cases} \\
n<0, \quad\left\langle x-x_{i}\right\rangle^{n}= \begin{cases}\infty, & x=x_{i} \\
0, & x \neq x_{i}\end{cases}
\end{array}\right.
$$

where $<>$ are Macaulay brackets. Singularity functions are introduced to Eqs (1) and (20) simultaneously. The damping component is negligible on account of little influence on natural properties of the plate and Eq. (1) reduces to

$$
\frac{\partial^{4} w}{\partial x^{4}}-\frac{N_{x}}{D} \frac{\partial^{2} w}{\partial x^{2}}+\frac{m(x)}{D} \frac{\partial^{2} w}{\partial t^{2}}=0
$$

with

$$
\left\{\begin{array}{l}
m(x)=m_{1}\left(\left\langle x-x_{0}\right\rangle^{0}-\left\langle x-x_{1}\right\rangle^{0}\right)+m_{2}\left(\left\langle x-x_{1}\right\rangle^{0}-\left\langle x-x_{2}\right\rangle^{0}\right) \\
m_{1}=\rho_{p} h \\
m_{2}=m_{1}+m_{\text {add }}
\end{array}\right.
$$

where $m_{1}$ and $m_{2}$ represent mass surface densities of non-immersed and immersed plates, respectively. $x_{0}, x_{1}$ and $x_{2}$ denote coordinates of boundaries for different regions of the plate. As shown in Fig. $2, x_{0}=0$ and $x_{2}=b$ are obvious in this paper. $m(x)$ can also be expressed as a segmented function

$$
m(x)= \begin{cases}m_{1}, & 0 \leqslant x<x_{1} \\ m_{2}, & x_{1} \leqslant x<b\end{cases}
$$

In order to investigate inherent properties of the system, the general solution of Eq. (22) can be defined as

$$
w=\sum_{j=1}^{\infty} X_{j}(x) \cdot\left(A \cos \omega_{j} t+B \sin \omega_{j} t\right)
$$

where $A$ and $B$ are two unknown constants to be determined. They are dependent on initial conditions. The substitution of Eq. (24) into Eq. (22) yields

$$
X_{j}^{(4)}-\frac{N_{x}}{D} X_{j}^{\prime \prime}-\frac{m(x) \omega_{j}^{2}}{D} X_{j}=0
$$




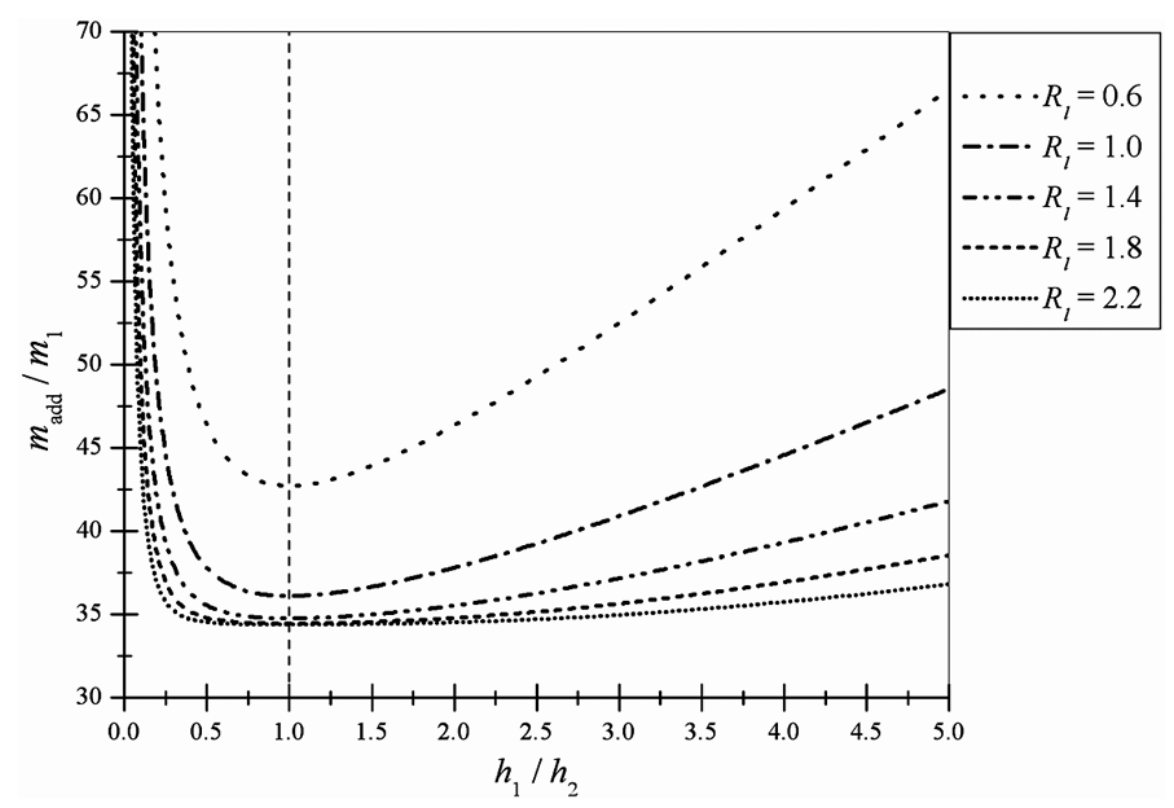

Fig. 3. Effect of plate position in a tank on added mass of a partially submerged plate.

where $X_{j}(x)$ and $\omega_{j}$ are the function of bending mode shape and the corresponding eigenfrequency (rad/s) of the thin plate, respectively. Considering Eq. (23), Eq. (25) may be rewritten as the following form

$$
\begin{cases}X_{j}^{(4)}-\frac{N_{x}}{D} X_{j}^{\prime \prime}-\frac{m_{1} \omega_{j}^{2}}{D} X_{j}=0, & 0 \leqslant x<x_{1} \\ X_{j}^{(4)}-\frac{N_{x}}{D} X_{j}^{\prime \prime}-\frac{m_{2} \omega_{j}^{2}}{D} X_{j}=0, & x_{1} \leqslant x<b\end{cases}
$$

Applying Laplace transform, the solution for the first equation of expression Eq. (26) is obtained and given by

$$
X_{j}=X_{j}(0) \psi_{1}(x)+X_{j}(0)^{\prime} \psi_{2}(x)+X_{j}(0)^{\prime \prime} \psi_{3}(x)+X_{j}(0)^{\prime \prime \prime} \psi_{4}(x), \quad\left(0 \leqslant x<x_{1}\right)
$$

where $\psi_{1}(x), \psi_{2}(x), \psi_{3}(x)$ and $\psi_{4}(x)$ are called influence functions [21]. Each of them is the function of $x$ coordinate as well as coefficients of the differential equation. They will have effect on the items of initial values and are given by expression Eq. (28).

$$
\left\{\begin{array}{l}
\psi_{1}(x)=\frac{1}{2 \beta}[(\beta-\alpha) \cosh (\sqrt{\alpha+\beta} x)+(\alpha+\beta) \cosh (\sqrt{\alpha-\beta} x)] \\
\psi_{2}(x)=\frac{1}{2 \beta}\left[\frac{(\beta-\alpha)}{\sqrt{\alpha+\beta}} \sinh (\sqrt{\alpha+\beta} x)+\frac{(\alpha+\beta)}{\sqrt{\alpha-\beta}} \sinh (\sqrt{\alpha-\beta} x)\right] \\
\psi_{3}(x)=\frac{1}{2 \beta}[\cosh (\sqrt{\alpha+\beta} x)-\cosh (\sqrt{\alpha-\beta} x)] \\
\psi_{4}(x)=\frac{1}{2 \beta}\left[\frac{1}{\sqrt{\alpha+\beta}} \sinh (\sqrt{\alpha+\beta} x)-\frac{1}{\sqrt{\alpha-\beta}} \sinh (\sqrt{\alpha-\beta} x)\right] \\
\alpha=\frac{N_{x}}{2 D} \\
\beta=\frac{\sqrt{N_{x}^{2}+4 D m(x) \omega_{j}^{2}}}{2 D}
\end{array}\right.
$$




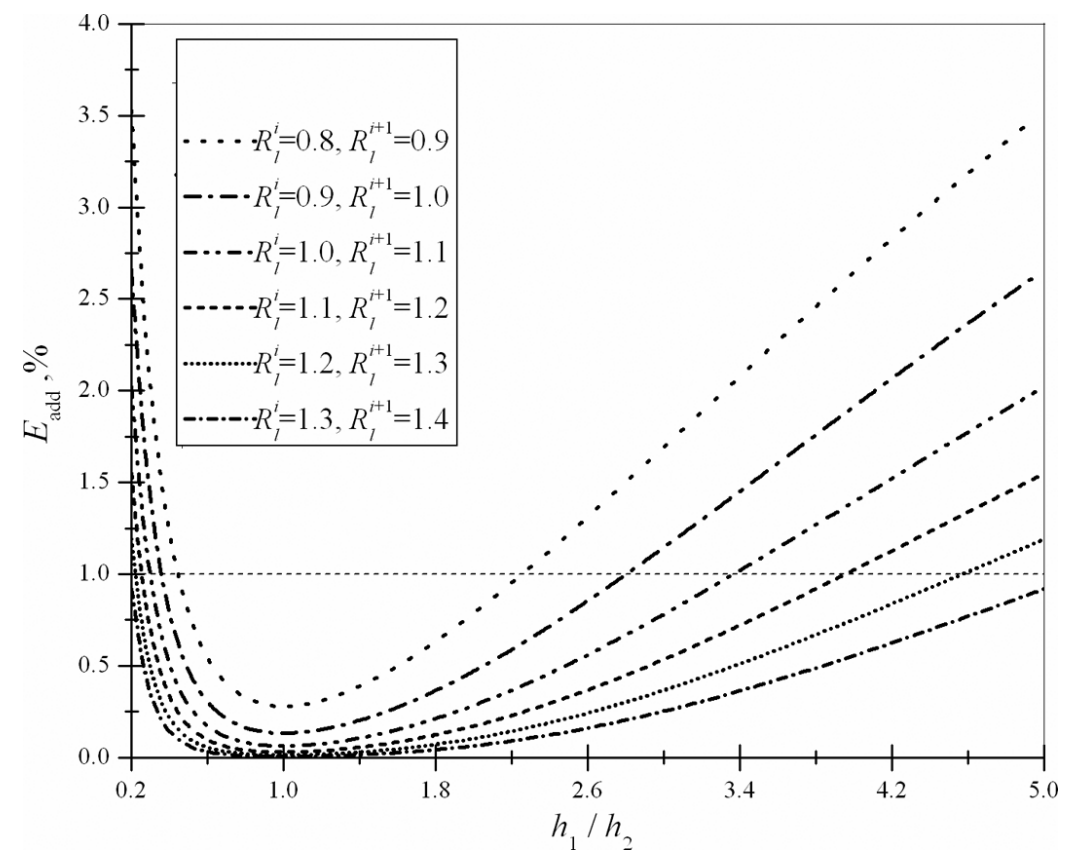

Fig. 4. Effect of tank width on added mass of a partially submerged plate.

Expression Eq. (28) can also be used in the solution for the second equation of Eq. (26) due to $m(x)$ being adopted in stead of $m_{1}(x)$ in the parameter $\beta$ which is defined in relation Eq. (28). Considering expression Eq. (27), one obtains $X_{j}$ and its first three order derivatives at $x=x_{1}$.

$$
\left\{\begin{array}{l}
X_{j}\left(x_{1}\right)=X_{j}(0) \psi_{1}\left(x_{1}\right)+X_{j}(0)^{\prime} \psi_{2}\left(x_{1}\right)+X_{j}(0)^{\prime \prime} \psi_{3}\left(x_{1}\right)+X_{j}(0)^{\prime \prime \prime} \psi_{4}\left(x_{1}\right) \\
X_{j}^{\prime}\left(x_{1}\right)=X_{j}(0) \psi_{1}^{\prime}\left(x_{1}\right)+X_{j}(0)^{\prime} \psi_{2}^{\prime}\left(x_{1}\right)+X_{j}(0)^{\prime \prime} \psi_{3}^{\prime}\left(x_{1}\right)+X_{j}(0)^{\prime \prime \prime} \psi_{4}^{\prime}\left(x_{1}\right) \\
X_{j}^{\prime \prime}\left(x_{1}\right)=X_{j}(0) \psi_{1}^{\prime \prime}\left(x_{1}\right)+X_{j}(0)^{\prime} \psi_{2}^{\prime \prime}\left(x_{1}\right)+X_{j}(0)^{\prime \prime} \psi_{3}^{\prime \prime}\left(x_{1}\right)+X_{j}(0)^{\prime \prime \prime} \psi_{4}^{\prime \prime}\left(x_{1}\right) \\
X_{j}^{\prime \prime \prime}\left(x_{1}\right)=X_{j}(0) \psi_{1}^{\prime \prime \prime}\left(x_{1}\right)+X_{j}(0)^{\prime} \psi_{2}^{\prime \prime \prime}\left(x_{1}\right)+X_{j}(0)^{\prime \prime} \psi_{3}^{\prime \prime \prime}\left(x_{1}\right)+X_{j}(0)^{\prime \prime \prime} \psi_{4}^{\prime \prime \prime}\left(x_{1}\right)
\end{array}\right.
$$

According to the continuity conditions of the plate, mid-surface displacements, rotation angles, bending moments and shear forces vary continuously at the interface of immersed and non-immersed plates. That is to say, $X_{j}, X_{j}^{\prime}$, $X_{j}^{\prime \prime}$ and $X_{j}^{\prime \prime \prime}$ change continuously at $x=x_{1}$. So the solution for the second equation of relation Eq. (26) can be determined by $X_{j}\left(x_{1}\right), X_{j}^{\prime}\left(x_{1}\right), X_{j}^{\prime \prime}\left(x_{1}\right), X_{j}^{\prime \prime \prime}\left(x_{1}\right)$ as follows

$$
\begin{aligned}
X_{j}= & X_{j}\left(x_{1}\right) \psi_{1}\left(x-x_{1}\right)+X_{j}\left(x_{1}\right)^{\prime} \psi_{2}\left(x-x_{1}\right) \\
& +X_{j}\left(x_{1}\right)^{\prime \prime} \psi_{3}\left(x-x_{1}\right)+X_{j}\left(x_{1}\right)^{\prime \prime \prime} \psi_{4}\left(x-x_{1}\right)
\end{aligned},\left(x_{1} \leqslant x<b\right)
$$

Placing relation Eq. (29) into Eq. (30) leads to the expression of $X_{j}$ as

$$
\begin{aligned}
X_{j}= & X_{j}(0) W \psi_{1}(x)+X_{j}(0)^{\prime} W \psi_{2}(x) \\
& +X_{j}(0)^{\prime \prime} W \psi_{3}(x)+X_{j}(0)^{\prime \prime \prime} W \psi_{4}(x)
\end{aligned},\left(x_{1} \leqslant x<b\right)
$$

in which the operator $W$ is defined by

$$
\left[\begin{array}{l}
W \psi_{1}(x) \\
W \psi_{2}(x) \\
W \psi_{3}(x) \\
W \psi_{4}(x)
\end{array}\right]=\left[\begin{array}{llll}
\psi_{1}\left(x_{1}\right) & \psi_{1}^{\prime}\left(x_{1}\right) & \psi_{1}^{\prime \prime}\left(x_{1}\right) & \psi_{1}^{\prime \prime \prime}\left(x_{1}\right) \\
\psi_{2}\left(x_{1}\right) & \psi_{2}^{\prime}\left(x_{1}\right) & \psi_{2}^{\prime \prime}\left(x_{1}\right) & \psi_{2}^{\prime \prime \prime}\left(x_{1}\right) \\
\psi_{3}\left(x_{1}\right) & \psi_{3}^{\prime}\left(x_{1}\right) & \psi_{3}^{\prime \prime}\left(x_{1}\right) & \psi_{3}^{\prime \prime \prime}\left(x_{1}\right) \\
\psi_{4}\left(x_{1}\right) & \psi_{4}^{\prime}\left(x_{1}\right) & \psi_{4}^{\prime \prime}\left(x_{1}\right) & \psi_{4}^{\prime \prime \prime}\left(x_{1}\right)
\end{array}\right]\left[\begin{array}{c}
\psi_{1}\left(x-x_{1}\right) \\
\psi_{2}\left(x-x_{1}\right) \\
\psi_{3}\left(x-x_{1}\right) \\
\psi_{4}\left(x-x_{1}\right)
\end{array}\right]
$$




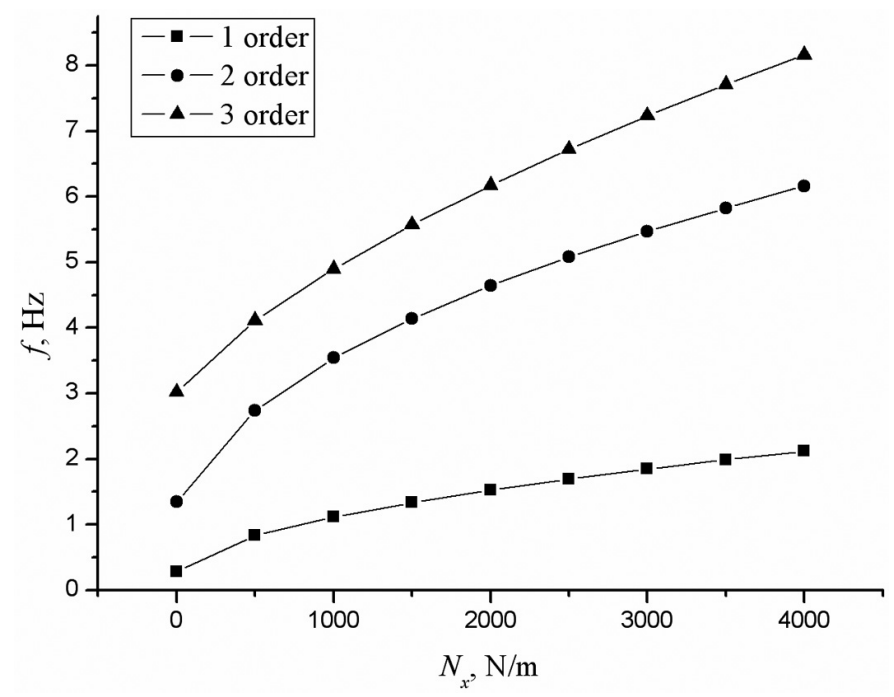

Fig. 5. Variations of natural bending frequencies with tension.

Taking Eqs (27) and (31) into account synthetically, the general solution of Eq. (25) can be written as

$$
\begin{aligned}
X_{j}= & X_{j}(0)\left[\left(\langle x-0\rangle^{0}-\left\langle x-x_{1}\right\rangle^{0}\right) \psi_{1}(x)+\left(\left\langle x-x_{1}\right\rangle^{0}-\langle x-b\rangle^{0}\right) W \psi_{1}(x)\right] \\
& +X_{j}^{\prime}(0)\left[\left(\langle x-0\rangle^{0}-\left\langle x-x_{1}\right\rangle^{0}\right) \psi_{2}(x)+\left(\left\langle x-x_{1}\right\rangle^{0}-\langle x-b\rangle^{0}\right) W \psi_{2}(x)\right] \\
& +X_{j}^{\prime \prime}(0)\left[\left(\langle x-0\rangle^{0}-\left\langle x-x_{1}\right\rangle^{0}\right) \psi_{3}(x)+\left(\left\langle x-x_{1}\right\rangle^{0}-\langle x-b\rangle^{0}\right) W \psi_{3}(x)\right] \\
& +X_{j}^{\prime \prime \prime}(0)\left[\left(\langle x-0\rangle^{0}-\left\langle x-x_{1}\right\rangle^{0}\right) \psi_{4}(x)+\left(\left\langle x-x_{1}\right\rangle^{0}-\langle x-b\rangle^{0}\right) W \psi_{4}(x)\right]
\end{aligned}
$$

Boundary conditions of simple supported at $x=0$ are given by

$$
X_{j}(0)=X_{j}^{\prime \prime}(0)=0
$$

Considering relation Eq. (33), expression Eq. (32) reduces to

$$
\begin{aligned}
X_{j}= & X_{j}^{\prime}(0)\left[\left(\langle x-0\rangle^{0}-\left\langle x-x_{1}\right\rangle^{0}\right) \psi_{2}(x)+\left(\left\langle x-x_{1}\right\rangle^{0}-\langle x-b\rangle^{0}\right) W \psi_{2}(x)\right] \\
& +X_{j}^{\prime \prime \prime}(0)\left[\left(\langle x-0\rangle^{0}-\left\langle x-x_{1}\right\rangle^{0}\right) \psi_{4}(x)+\left(\left\langle x-x_{1}\right\rangle^{0}-\langle x-b\rangle^{0}\right) W \psi_{4}(x)\right]
\end{aligned}
$$

Similarly, boundary conditions of simple supported at $x=b$ can be written as

$$
X_{j}(b)=X_{j}^{\prime \prime}(b)=0
$$

The introduction of relation Eq. (35) into expression Eq. (34) results in the following equations set

$$
\left\{\begin{array}{l}
X_{j}^{\prime}(0)\left[W \psi_{2}(b)\right]+X_{j}^{\prime \prime \prime}(0)\left[W \psi_{4}(b)\right]=0 \\
X_{j}^{\prime}(0)\left[W \psi_{2}(b)\right]^{\prime \prime}+X_{j}^{\prime \prime \prime}(0)\left[W \psi_{4}(b)\right]^{\prime \prime}=0
\end{array}\right.
$$

An eigenvalue equation can be obtained from relation Eq. (36) as follows

$$
\left|\begin{array}{cc}
{\left[W \psi_{2}(b)\right]} & {\left[W \psi_{4}(b)\right]} \\
{\left[W \psi_{2}(b)\right]^{\prime \prime}} & {\left[W \psi_{4}(b)\right]^{\prime \prime}}
\end{array}\right|=0
$$

Natural frequencies of bending vibration for a partially submerged plate are calculated by solving Eq. (37) numerically. The corresponding mode shapes of the plate can be further achieved with Eqs (36) and (34). In this paper, formula derivations are accomplished by using Mathematica software [22]. 

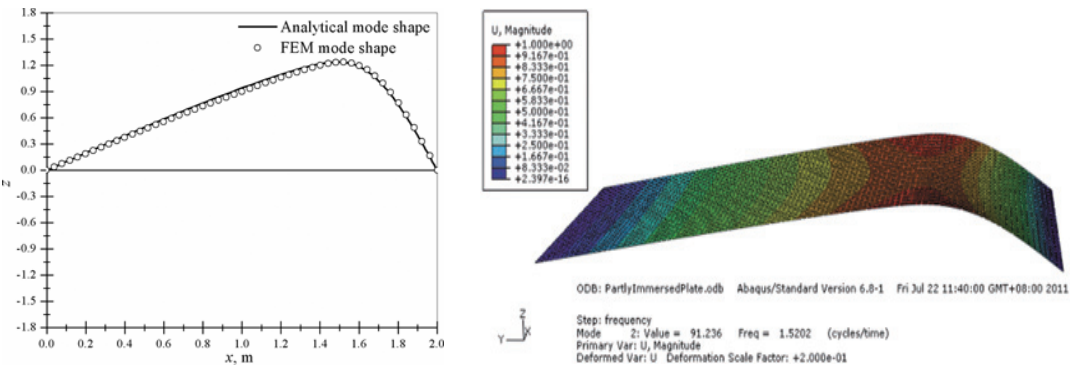

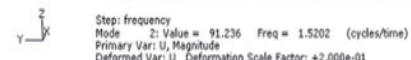

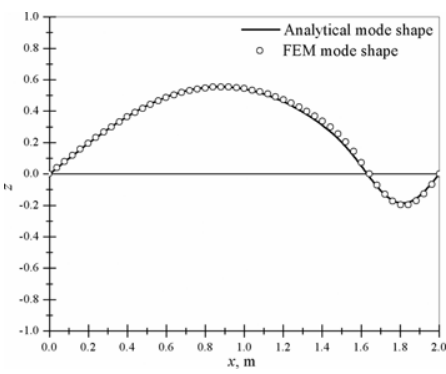

(a)
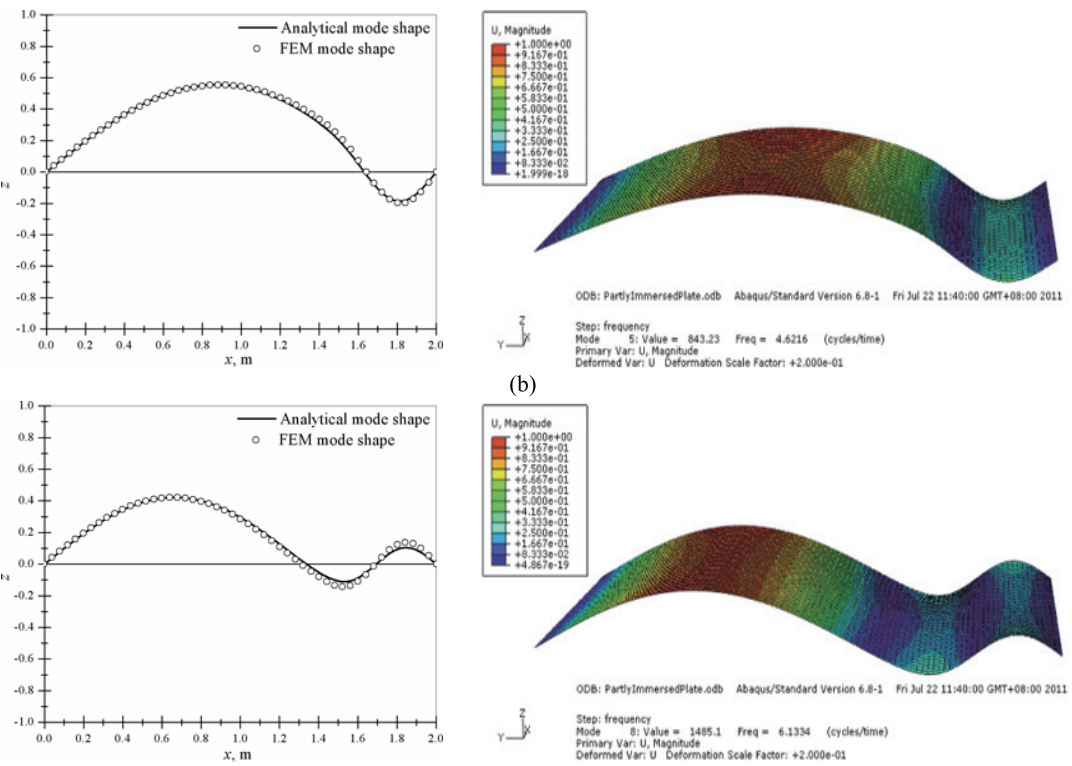

(b)
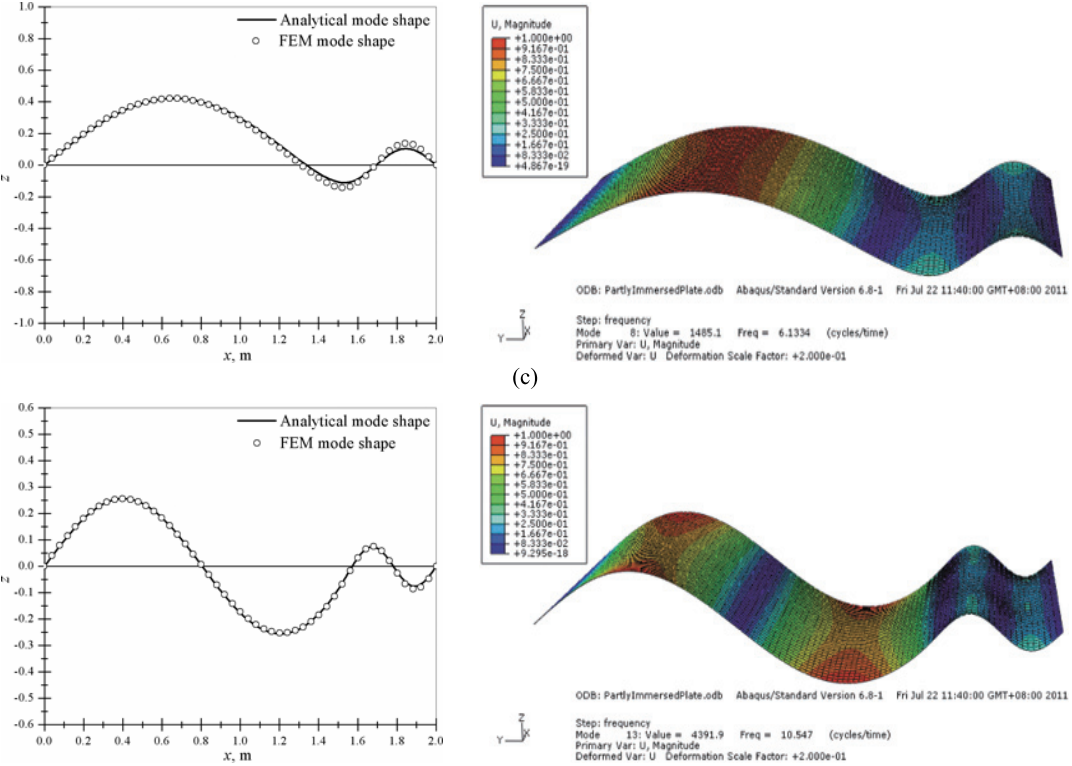

(c)
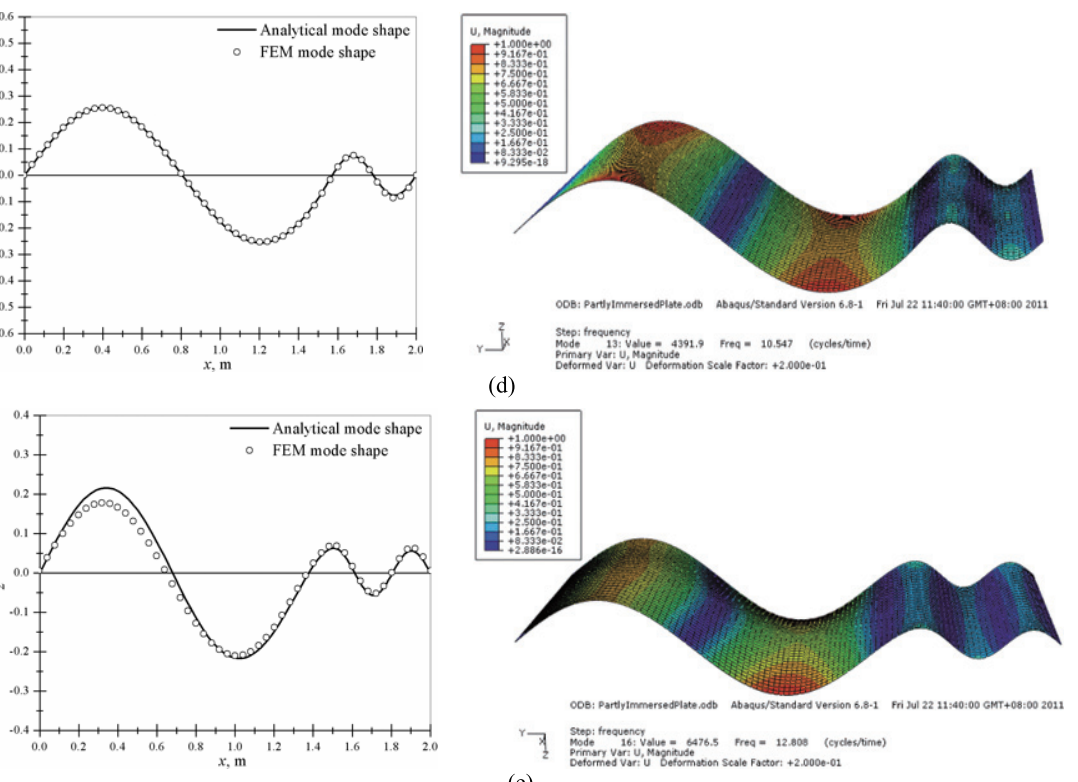

Fig. 6. Comparisons of the first five vibration modes between using SFM and FEM. (a) The first vibration mode; (b) the second vibration mode; (c) the third vibration mode; (d) the fourth vibration mode; (e) the fifth vibration mode. 
Table 1

Comparisons of the first five natural frequencies between using SFM and FEM

\begin{tabular}{crcc}
\hline Mode number & SFM $(\mathrm{Hz})$ & FEM $(\mathrm{Hz})$ & Error $(\%)$ \\
\hline 1 & 1.5252 & 1.5202 & 0.33 \\
2 & 4.6418 & 4.6216 & 0.44 \\
3 & 6.1718 & 6.1334 & 0.63 \\
4 & 10.6008 & 10.547 & 0.51 \\
5 & 12.8643 & 12.808 & 0.44 \\
\hline
\end{tabular}

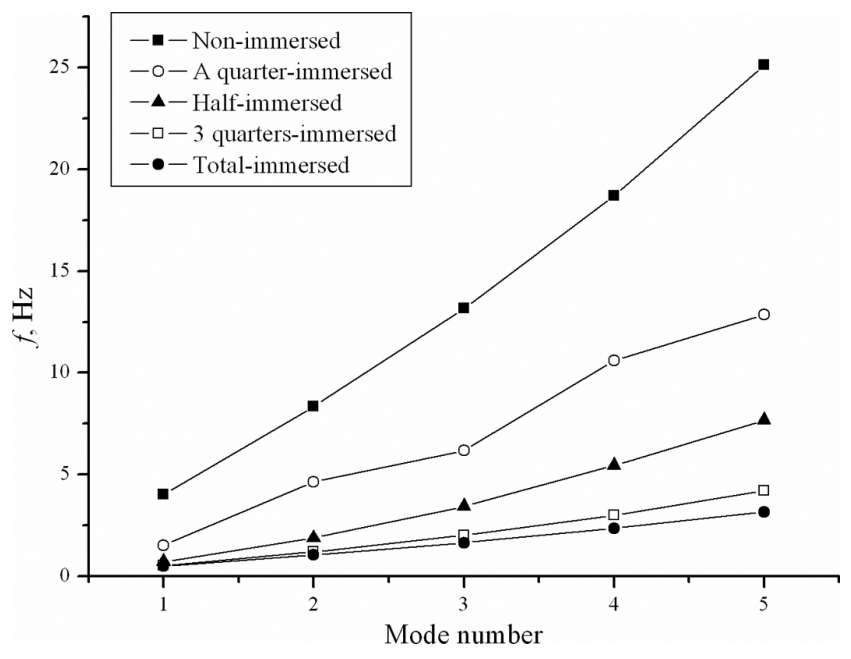

Fig. 7. Comparisons of the first five natural frequencies for plates with various submerged depths by using the presented analytical method.

\section{Results and discussions}

In this paper, inherent properties of the partially immersed plate obtained by using the proposed theory are compared with results of FEM to show the reliability of the presented formulation. Finally, natural frequencies and vibration modes of the system can be easily acquired by solving the eigenvalue problem with a numerical iteration method. Dimensions and properties of the plate and fluid in the following example are: $a=0.8 \mathrm{~m}, b=2 \mathrm{~m}$, $h=0.001 \mathrm{~m}, \nu=0.3, E=2.03 \times 10^{11} \mathrm{~Pa}, \rho_{p}=7850 \mathrm{~kg} / \mathrm{m}^{3}, \rho_{f}=1000 \mathrm{~kg} / \mathrm{m}^{3}$. Figure 3 shows the relationship between added mass and the position of plate located in a reservoir, when the depth ratio of the partially submerged plate is $1 / 4$ (i.e. $\left(b-x_{1}\right) / b=0.25$ ). During the investigation, a relevant dimensionless parameter $R_{l}$ is define as

$$
R_{l}=\left(h_{1}+h_{2}\right) /\left(b-x_{1}\right)
$$

where $R_{l}$ denotes the ratio of reservoir width to the submerged depth of the plate. As shown in Fig. 3, the added mass has a minimum value when the partially submerged plate is located in the very middle of the tank (i.e. $h_{1} / h_{2}=1$ ). The value of added mass will augment rapidly with the increasing of deviation of the plate from the middle position of the tank and approach infinity when the plate is close to the boundary of the tank. From Fig. 3 we can also see that the bigger $R_{l}$ is, the flatter the curve tends to be, that is, the sensitivity of added mass to plate position weakens gradually.

Influences of tank width upon added mass of a quarter-immersed plate are analyzed further and plotted in Fig. 4. The following dimensionless parameter $E_{\text {add }}$ is introduced to help develop the research.

$$
E_{\text {add }}=\left[\left(\left.m_{\text {add }}\right|_{R_{l}=R_{l}^{i}}-\left.m_{\text {add }}\right|_{R_{l}=R_{l}^{i+1}}\right) /\left.m_{\text {add }}\right|_{R_{l}=R_{l}^{i+1}}\right] \times 100 \% \quad(i=1,2, \ldots)
$$

where $E_{\text {add }}$ represents error of added mass with different $R_{l}$.

As observed in Fig. 4, the relative error of added mass between at $R_{l}=1.4$ and at $R_{l}=1.3$ is less than $1 \%$ in the case of the plate keeping off tank walls (i.e. $1 / 5 \leqslant h_{1} / h_{2} \leqslant 5$ ). So we can deduce the conclusion that increase of tank width has little effect on the value of added mass when the ratio of tank width to the submerged depth of the plate is greater than 1.3.

Figure 5 shows the variations of the three lowest natural bending frequencies with tension for a quarter-immersed plate. The relation between the natural frequency $f(\mathrm{~Hz})$ appeared in Fig. 5 and the eigenfrequency $\omega_{j}$ is $f=\omega_{j} / 2 \pi$. The analysis is carried out at $x_{1}=1.5 \mathrm{~m}$ and $h_{1}=h_{2}=0.5 \mathrm{~m}$. Other dimensions and properties of the system are the same as stated above. It is noted that natural frequencies of the partially submerged plate have a strong dependence on tension and appear to be increased remarkably with increasing tension. 


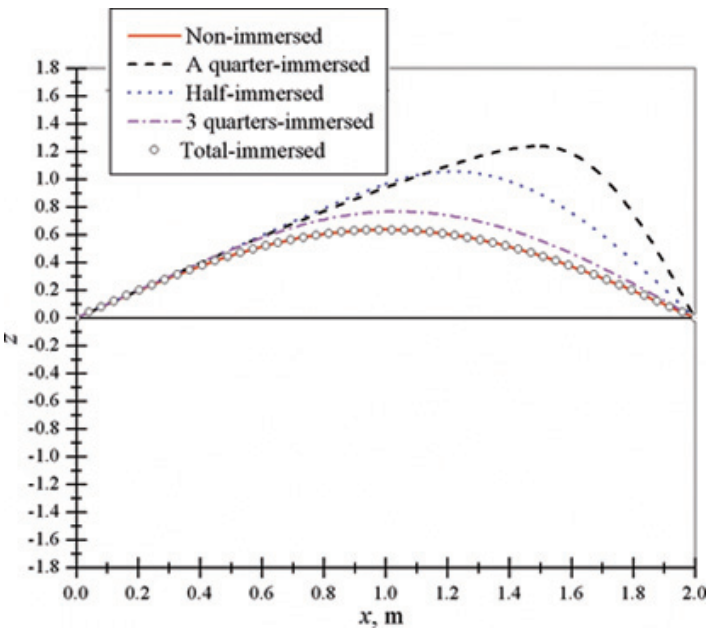

(a)

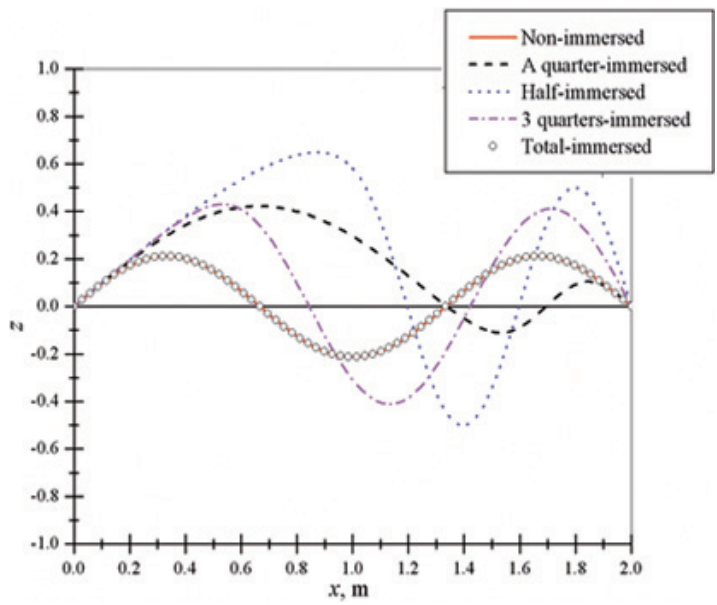

(c)

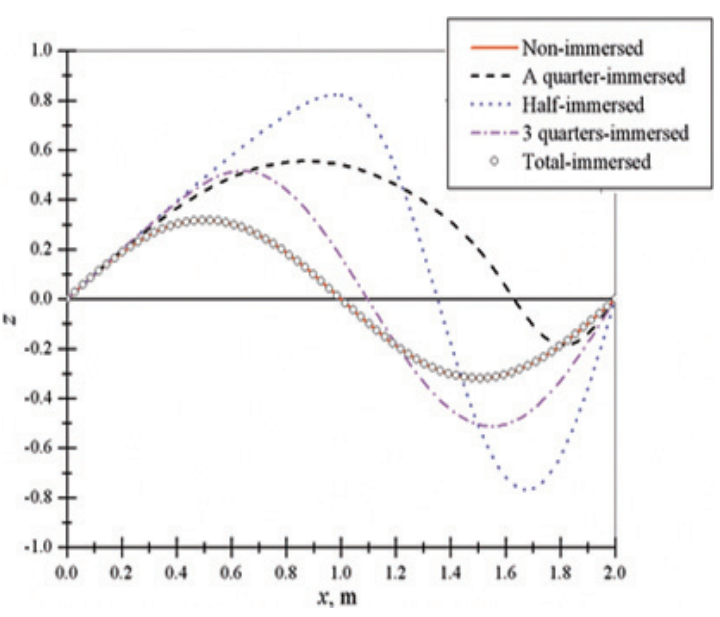

(b)

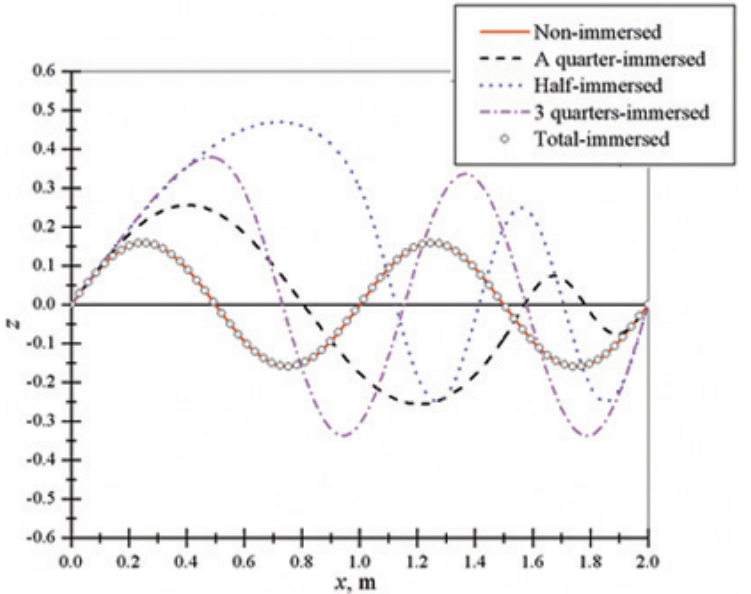

(d)

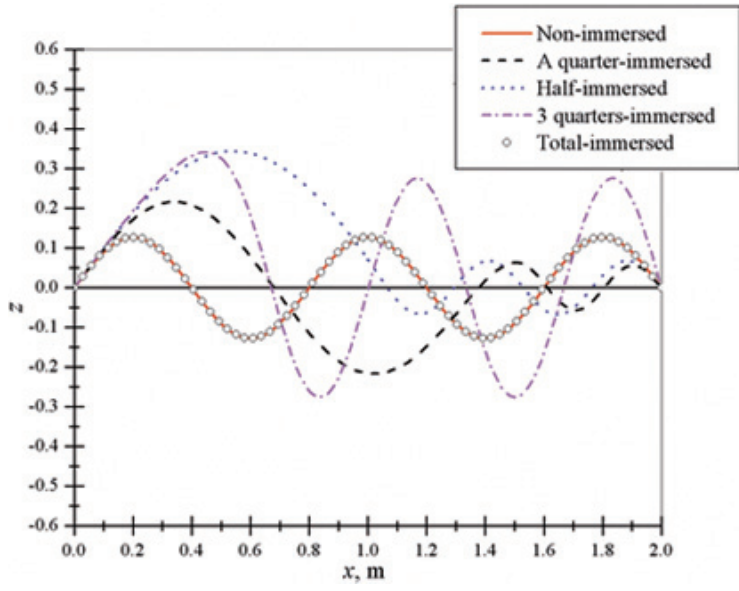

(e)

Fig. 8. Differences of the first five vibration modes for plates with various submerged depths by using the presented analytical method. (a) The first vibration mode; (b) the second vibration mode; (c) the third vibration mode; (d) the fourth vibration mode; (e) the fifth vibration mode. 
To verify the reliability of the presented approach, inherent properties of the partially immersed plate gotten by singularity function method (SFM) compare with results calculated by FEM. Free vibration frequencies and principal mode shapes of the simple supported plate with discontinuous characteristics are obtained by use of ABAQUS [23], a standard finite-element software. The plate is discretized by four-noded, doubly curved thin shell elements, including influences of reduced integration, hourglass control and finite membrane strains. The LANCZOS [23] method is employed to study inherent properties of the plate, taking account of tension. SFM and ABAQUS are provided to investigate the first five natural frequencies and mode shapes of a quarter-immersed plate simultaneously. Comparisons of the results obtained with these two methods are listed in Table 1 and shown in Fig. 6, respectively. Furthermore, displacement contour plots for various flexural vibration modes of the plate are also given in Fig. 6. Dimensions and properties of the system used in the numerical examples are the same as those mentioned above besides the tension $N_{x}=2000 \mathrm{~N} / \mathrm{m}$. As can be seen in Table 1 and Fig. 6, a good agreement between the results of SFM and the values with ABAQUS confirms the validity of the proposed theory.

Using the proposed analytical method developed above, comparisons of natural frequencies and modes between non-immersed, a quarter-immersed, half-immersed, three quarters-immersed and total-immersed plates are made in Figs 7 and 8. According to the results depicted in these figures, we can conclude that fluid has a great influence on inherent properties of a vibrating plate. It is also noted that natural frequencies exhibit a significant decrease with the increasing of submerged depth of the plate. In addition, vibration modes of the partially immersed plate are remarkably different from those of the non-immersed plate. Nevertheless, as can be seen in Fig. 8, the mode shape of non-immersed plate is almost the same as that of total-immersed plate. To provide a set of benchmark values for solving such problems, natural frequencies of a partially immersed plate with different parameters $a, b, h_{1}, h_{2}$, and $x_{1}$ are studied and checked with FEM results (see appendix).

\section{Conclusions}

The main objective of the investigation described in this paper is to put forward a new analytical method for the inherent properties of a tensioned, unidirectional vibrating plate partially submerged in liquid. The results show that the calculations based on the proposed approach are in very good agreement with the data of FEM. It can also be concluded from the results that fluid has a significant influence on natural frequencies as well as mode shapes of a vibrating plate. This type of influence may be treated as added mass of the plate. The magnitude of added mass is associated with plate position in a tank, the submerged depth of the plate and tank width. The added mass reaches the minimum in the case of the plate being located in the very middle of the reservoir. As the ratio of tank width to the submerged depth of the plate is greater than 1.3, increase of tank width can be ignored in the calculation of added mass under the condition of the plate keeping off tank walls. Singularity functions are employed to unify segmental dynamics equations of the partially submerged plate. The unified dynamics equation is solved analytically by using Laplace transform. Furthermore, it is worthy to note that the proposed approach in this paper can be applied to the analytical study of vertical or angled plates subjected to other boundary conditions. The provided method can further be used to investigate non-uniform plate in complicated environment, such as the tensioned plate with discontinuous materials and rigidity as well as with different types of pressure fields around.

The unidirectional vibrating thin plate studied in this paper is essentially the same as an Euler-Bernoulli beam. The influences of shear deformation and rotary inertia are neglected. In general, the effects of transverse shear deformations must be considered in the case of the ratio of thickness to the minimum span of the plate being larger than 1/6. Correspondingly, the analysis should be based on the theory of Timoshenko beam for a unidirectional vibrating plate or on the theory of middle-thick plate for flexural and torsional vibrations of an elastic plate (e.g. the theories of Hencky, Reissner, Kromm, Panc and Donnell, etc.).

\section{Acknowledgments}

This work was supported by the National Natural Science Foundation of China (Grant No. 11172063). This support is gratefully acknowledged. The authors would also like to thank the reviewers for their useful comments. 


\section{Appendix}

The first three natural frequencies of the plate with different parameters $a, b, h_{1}, h_{2}$ and $x_{1}$ are listed in the table below and checked with FEM results.

\begin{tabular}{|c|c|c|c|c|c|c|c|c|c|c|}
\hline \multirow[b]{2}{*}{ Dimensions } & \multirow[t]{2}{*}{ Mode No. } & \multicolumn{3}{|c|}{1} & \multicolumn{3}{|c|}{2} & \multicolumn{3}{|c|}{3} \\
\hline & & $\begin{array}{l}\text { SFM } \\
(\mathrm{Hz})\end{array}$ & $\begin{array}{c}\text { FEM } \\
(\mathrm{Hz})\end{array}$ & $\begin{array}{c}\text { Error } \\
(\%)\end{array}$ & $\begin{array}{l}\text { SFM } \\
(\mathrm{Hz})\end{array}$ & $\begin{array}{c}\text { FEM } \\
(\mathrm{Hz})\end{array}$ & $\begin{array}{c}\text { Error } \\
(\%)\end{array}$ & $\begin{array}{l}\text { SFM } \\
(\mathrm{Hz})\end{array}$ & $\begin{array}{c}\text { FEM } \\
(\mathrm{Hz})\end{array}$ & $\begin{array}{c}\text { Error } \\
(\%) \\
\end{array}$ \\
\hline$b=2.0 \mathrm{~m}$ & $a=1.0 \mathrm{~m}$ & 1.488 & 1.483 & 0.34 & 4.576 & 4.553 & 0.50 & 6.098 & 6.035 & 1.03 \\
\hline$x_{1}=1.5 \mathrm{~m}$ & $a=2.0 \mathrm{~m}$ & 1.433 & 1.416 & 1.19 & 4.468 & 4.425 & 0.96 & 5.998 & 5.917 & 1.35 \\
\hline $\begin{array}{l}h_{1}=0.5 \mathrm{~m} \\
h_{2}=0.5 \mathrm{~m}\end{array}$ & $a=3.0 \mathrm{~m}$ & 1.422 & 1.390 & 2.25 & 4.445 & 4.334 & 2.50 & 5.979 & 5.812 & 2.79 \\
\hline$a=0.8 \mathrm{~m}$ & $b=2.5 \mathrm{~m}$ & 0.675 & 0.674 & 0.15 & 1.842 & 1.836 & 0.33 & 3.372 & 3.352 & 0.59 \\
\hline$x_{1}=1.5 \mathrm{~m}$ & $b=3.0 \mathrm{~m}$ & 0.447 & 0.447 & 0 & 1.121 & 1.117 & 0.36 & 2.924 & 2.90 & 0.82 \\
\hline $\begin{array}{l}h_{1}=0.5 \mathrm{~m} \\
h_{2}=0.5 \mathrm{~m}\end{array}$ & $b=3.5 \mathrm{~m}$ & 0.342 & 0.342 & 0 & 0.815 & 0.813 & 0.25 & 1.366 & 1.361 & 0.37 \\
\hline$a=0.8 \mathrm{~m}$ & $x_{1}=0$ & 0.509 & 0.508 & 0.20 & 1.051 & 1.047 & 0.38 & 1.659 & 1.649 & 0.60 \\
\hline$b=2.0 \mathrm{~m}$ & $x_{1}=0.5 \mathrm{~m}$ & 0.545 & 0.544 & 0.18 & 1.208 & 1.203 & 0.41 & 2.022 & 2.008 & 0.69 \\
\hline$h_{1}=0.5 \mathrm{~m}$ & $x_{1}=1.0 \mathrm{~m}$ & 0.722 & 0.721 & 0.14 & 1.881 & 1.873 & 0.43 & 3.438 & 3.415 & 0.67 \\
\hline$h_{2}=0.5 \mathrm{~m}$ & $x_{1}=1.5 \mathrm{~m}$ & 1.525 & 1.520 & 0.33 & 4.642 & 4.622 & 0.43 & 6.172 & 6.133 & 0.63 \\
\hline & $x_{1}=2.0 \mathrm{~m}$ & 4.037 & 4.032 & 0.12 & 8.346 & 8.313 & 0.40 & 13.17 & 13.09 & 0.61 \\
\hline$a=0.8 \mathrm{~m}$ & $h_{1}=0.1 \mathrm{~m}$ & 1.355 & 1.350 & 0.37 & 4.298 & 4.275 & 0.54 & 5.874 & 5.839 & 0.60 \\
\hline$b=2.0 \mathrm{~m}$ & $h_{1}=0.4 \mathrm{~m}$ & 1.524 & 1.519 & 0.33 & 4.639 & 4.619 & 0.43 & 6.169 & 6.131 & 0.62 \\
\hline $\begin{array}{l}x_{1}=1.5 \mathrm{~m} \\
h_{2}=0.5 \mathrm{~m}\end{array}$ & $h_{1}=0.7 \mathrm{~m}$ & 1.526 & 1.521 & 0.33 & 4.643 & 4.622 & 0.45 & 6.173 & 6.134 & 0.63 \\
\hline
\end{tabular}

\section{References}

[1] H. Lamb, On the vibrations of an elastic plate in contact with water, Proceedings of the Royal Society of London, Series A 98 (1921), 205-216.

[2] J.H. Powell and J.H.T. Roberts, On the frequency of vibration of circular diaphragms, Proceedings of the Physical Society of London 35 (1923), 170-182.

[3] Y. Kozlovsky, Vibration of plates in contact with viscous fluid: Extension of Lamb's model, Journal of Sound and Vibration 326 (2009), 332-339.

[4] U.S. Lindholm, D.D. Kana, W.H. Chu and H.N. Abramson, Elastic vibration characteristics of cantilever plates in water, Journal of Ship Research 9 (1965), 11-22.

[5] Y. Fu and W.G. Price, Interactions between a partially or totally immersed vibrating cantilever plate and the surrounding fluid, Journal of Sound and Vibration 118 (1987), 495-513.

[6] Y. Fu, W.G. Price and P. Temarel, The 'dry and wet' towage of a jack-up in regular and irregular waves, Transactions of the Royal Institution of Naval Architects 129 (1987), 149-159.

[7] C.C. Liang, C.C. Liao, Y.S. Tai and W.H. Lai, The free vibration analysis of submerged cantilever plates, Ocean Engineering 28 (2001), 1225-1245.

[8] Y. Yadykin, V. Tenetov and D. Levin, The added mass of a flexible plate oscillating in a fluid, Journal of Fluids and Structures 17 (2003), 115-123.

[9] A. Ergin and B. Ugurlu, Linear vibration analysis of cantilever plates partially submerged in fluid, Journal of Fluids and Structures 17 (2003), 927-939.

[10] C. Atkinson and M.M. de Lara, The frequency response of a rectangular cantilever plate vibrating in a viscous fluid, Journal of Sound and Vibration 300 (2007), 352-367.

[11] K. Nagaya and J. Takeuchi, Vibration of a plate with arbitrary shape in contact with a fluid, Journal of the Acoustical Society of America 75 (1984), 1511-1518.

[12] M. Amabili, Bulging modes of circular bottom plates in rigid cylindrical containers filled with a liquid, Shock and Vibration 4 (1997), $51-66$

[13] M.R. Haddara and S. Cao, A study of the dynamic response of submerged rectangular flat plates, Marine Structure 9 (1996), 913-933.

[14] T.P. Chang and M.F. Liu, On the natural frequency of a rectangular isotropic plate in contact with fluid, Journal of Sound and Vibration 236 (2000), 547-553.

[15] N.J. Robinson and S.C. Palmer, A modal analysis of a rectangular plate floating on an incompressible liquid, Journal of Sound and Vibration 142 (1990), 453-460.

[16] M.K. Kwak and K.C. Kim, Axisymmetric vibration of circular plates in contact with fluid, Journal of Sound and Vibration 146 (1991), 381-389. 
[17] G. Muthuveerappan, N. Ganesan and M.A. Veluswami, Note on vibration of a cantilever plate immersed in water, Journal of Sound and Vibration 63 (1979), 385-391.

[18] E. Hernandez, Approximation of the vibration modes of a plate and shells coupled with a fluid, Journal of Applied Mechanics 73 (2006), $1005-1010$.

[19] C. Eloy, C. Souilliez and L. Schouveiler, Flutter of a rectangular plate, Journal of Fluids and Structures 23 (2007), 904-919.

[20] Y. Kerboua, A.A. Lakis, M. Thomas and L. Marcouiller, Vibration analysis of rectangular plates coupled with fluid, Applied Mathematical Modelling 32 (2008), 2570-2581.

[21] X.S. Wang, Singularity functions and its applications in mechanics, Science Press, Beijing, 1993, pp. 1-59. (In Chinese)

[22] S. Wolfram, The mathematica book, Cambridge University Press, Cambridge, 1999.

[23] ABAQUS Inc., ABAQUS documentation version 6.5, ABAQUS Inc., Rawtucket, Rhode Island, 2004. 

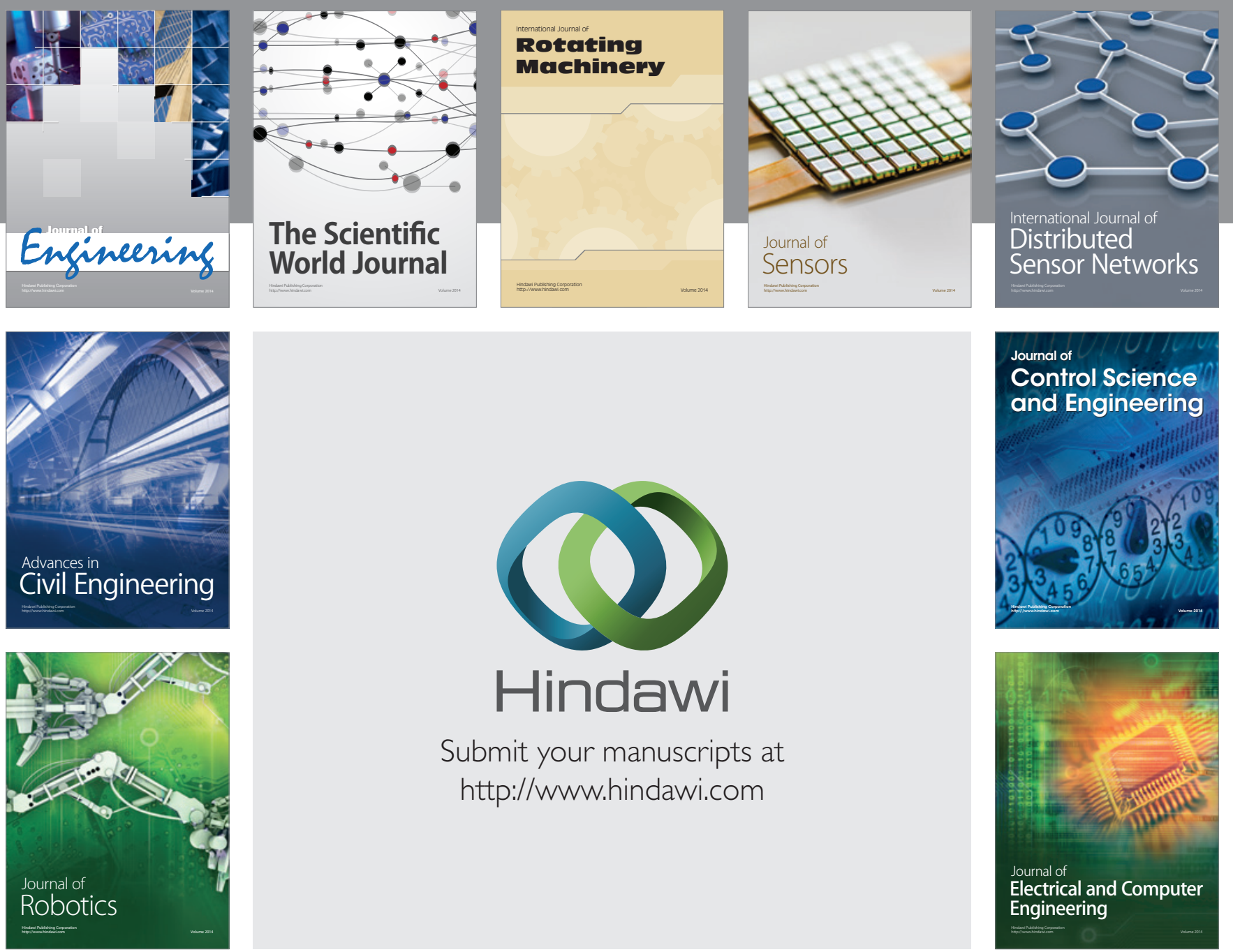

Submit your manuscripts at

http://www.hindawi.com
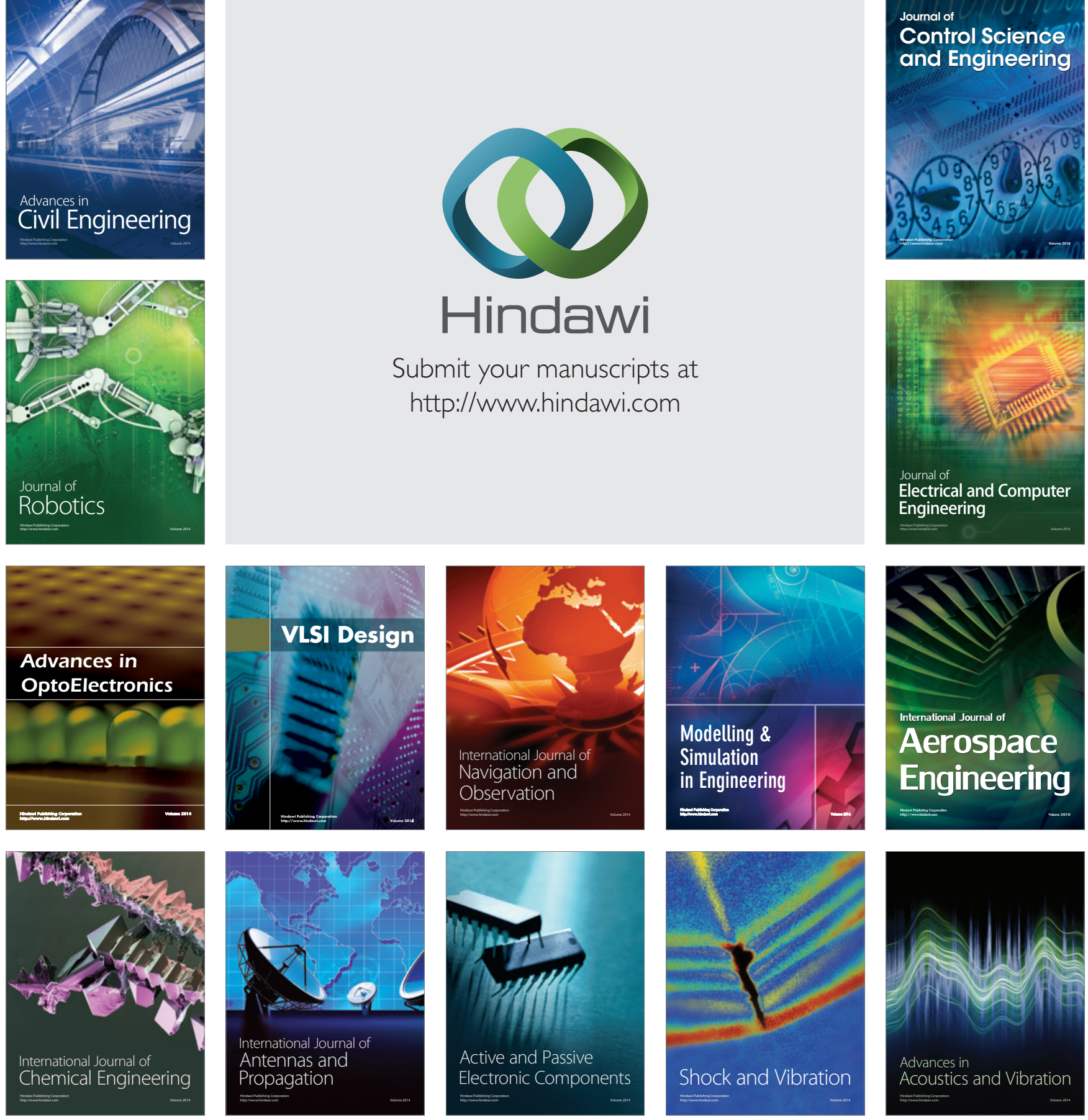